\title{
RESEARCH AND ETHICAL ISSUES ARISING FROM ETHNOGRAPHIC INTERVIEWS OF PATIENTS' REACTIONS TO AN INTELLIGENT INTERACTIVE TELEPHONE HEALTH BEHAVIOR ADVISOR
}

\author{
Bonnie Kaplan \\ Yale University School of Medicine \\ U.S.A. \\ Ramesh Farzanfar \\ Robert H. Freeman \\ Medical Information Systems Unit \\ Boston University \\ U.S.A.
}

\begin{abstract}
People develop strong reactions to machines. Among those reactions are personal relationships that people form with technological objects. Exploration of ways in which individuals relate to information technologies and how individuals see these technologies as being machine-like or being human-like is a fascinating and useful research area. This paper presents a study where these issues arose as a key, although unanticipated, theme in ethnographic interviews conducted among individuals using an intelligent interactive telephone system, Telephone-Linked Care (TLC), that provided counseling about health behaviors. Many interviewees expressed ambiguity over whether they were talking to a machine or to a person during TLC conversations. Interview findings suggest that people formed personal relationships
\end{abstract}


with the TLC system, or at least with the voice on the telephone. These relationships ranged from feeling guilty about their diet or exercise behavior to feeling love for the voice.

Relationship formation with information technology is of special concern in areas such as medicine and health care in light of the debate over whether computers dehumanize patients. However, this concern pertains to other applications of information technology as well. The findings in this study raise ethical issues and the need for further research.

The value of ethnographic interviewing also is illustrated by this study. Ethnographic interviewing allowed new ideas-in this case, people's relationship formation with information technology-to emerge and, thereby, provided the possibility for future studies and the potential development of theory.

Keywords: Social and organizational issues, ethical issues, qualitative research, social informatics, medical and health care informatics, information systems evaluation, ethnographic interviewing, personal relationships with technology.

\section{Introduction}

It has long been recognized that people form relationships with technological objects. They can become attached to their automobiles (Rae 1965), for example, or they may see dynamos as symbols of an age (Adams 1918). A propensity for projecting human qualities onto things is apparent when people anthropomorphize computer technology. As psychologist Robert F. Bayles observed, "The computer is the ultimate Rorschach test" (quoted in Nelson 1974, p. 9). This observation was fleshed out in the work of Sherry Turkle $(1982,1984)$. She described how people project onto computers their own aspirations, ideologies, hopes, and politics. She argued that people of all ages, from school children to researchers in artificial intelligence at the Massachusetts Institute of Technology, use computers and related technology, such as video games, in ways that explore the boundaries between human and machine. In so doing, the people Turkle studied considered what it means to be human by thinking about what differentiates a person from a machine such as a computer. Computers, she explains, are evocative objects, well-suited to think with about such questions. They are just human-like enough to raise difficult questions, such as whether a machine can cheat. They are protean enough to serve as projective devices, much like the Rorschach ink blots, or, as Turkle described, other technological objects such as gears or mirrors. Mechanical dolls and similar automatons are both fascinating and disturbing for much the same reasons as are computers: they share similarities and differences with humans.

The issue of what human qualities are shared by computers, and what implications this poses, is not new. Alan Turing raised it in a famous paper as early as 1950 in which he proposed what came to be called the Turing Test as a way of answering the question, "Can Machines Think?" (Turing 1950 - this paper has been published and reprinted under various titles). Since then, there has been a distinguished philosophical literature concerning this question, while new fields of psychology developed in which human mental functioning is explained in information processing terms. Zuboff (1988) raised 
related issues when considering how to design and use information technologies that replace human mental labor when she explored implications of automating vs. "informating" work. There has been extensive concern in the sociological literature, and some in the Information Systems literature, about how information technology can support work or dehumanize individuals.

Such questions become particularly important when information technologies are used in personal areas such as health care. As patient-centered health care grows in popularity, it is becoming more common place for information technology to be used to collect data directly from patients and to provide educational information to them. Such systems have been evaluated in terms of quality of data gathered from patients (Hunt et al. 1997), how satisfied patients are with such methods (Kim et al. 1997), and health outcomes for patients who use such systems (Balas, Boren, and Griffing 1998). Little has been done, however, to understand patients' reactions to such systems (Forsythe 1996). Concern over patient reactions is especially important in light of the debate over whether computers dehumanize patients (Shortliffe 1994).

Ways in which individuals relate to information technologies and how individuals see these technologies as being machine-like or being human-like is a fascinating area that needs more exploration. This paper presents a study where this issue arose as a key theme in ethnographic interviews conducted among individuals using an intelligent interactive telephone system that provided counseling about health behaviors. Although it was not an initial goal of the study, interviewees unexpectedly expressed ideas and feelings that suggest that they formed strong personal relationships with the system. They identified with the system in various ways and projected deep personal concerns onto it, while also expressing ambiguity and ambivalence over whether they were dealing with a person or a machine.

The value of ethnographic interviewing also is illustrated by this study. That so interesting and powerful a theme arose when it was unanticipated indicates that the study could not have been designed to explicitly address this issue. Ethnographic interviewing allowed new ideas to emerge during the course of the study and, thereby, provided the possibility for future studies and the potential development of theory (Glaser and Strauss 1967; Kaplan and Maxwell 1994).

\section{Telephone-Linked Care}

The Telephone-Linked Care (TLC) system is an intelligent interactive telephone system that uses interactive voice response technology to conduct a series of brief (approximately five minute) conversations with patients in their homes over their telephones. TLC uses a pre-recorded digitized human voice to speak to users. It can ask questions; respond to users' answers to those questions; and provide information, advice, and counseling. TLC has been used for a variety of health purposes, including disease monitoring and health behavior counseling (Friedman 1998; Friedman et al. 1997; Friedman et al. 1998). TLC-HealthCall is a TLC application that advises individuals on improving their health either through changes in diet or exercise, depending upon which version of the system an individual used. TLC spoke to users according to a script that was recorded by a human male voice professional. Participants called the system once weekly for a maximum of 26 weeks. By using the telephone keypad for input, they provided information in answer to questions TLC asked them. TLC then responded to this information with comparisons to their previous behavior and suggestions for future 
behavior. For example, TLC might have asked someone how much exercise he had had that week, or how many servings of vegetables she had eaten. In response to the person's response, TLC might praise the individual for increasing the amount of exercise done, urge the person to eat more vegetables, and provide suggestions for how to incorporate vegetables into the diet.

\section{Methods}

\subsection{Interviewee Selection}

An evaluation of TLC-HealthCall is being conducted to investigate a variety of health related questions. One aspect of this research includes a multi-method assessment of individuals' reactions to using TLC (Kaplan 1997; Kaplan and Duchon 1988). Among the evaluation research questions were what patients thought about using the system, whether they were satisfied with it, how it actually helped them, and what meaning individuals made out of their experience with TLC. Ethnographic or qualitative methods are especially useful for this kind of evaluation (Kaplan and Maxwell 1994).

The total number of individuals who completed the TLC-HealthCall study was 247. Of them, 215 were women and 83 were men. From these 247 people, 15 were interviewed in depth during a one-week period after they had completed 26 weeks of potential TLC use. Interviewees were selected so as to include:

(1) individuals representative of the entire population in the study,

(2) individuals who represented outliers of specific interest to the study, and

(3) individuals who had the potential to be helpful informants.

All interviewees had completed an exit telephone survey with a member of the research staff. The survey protocol was a lengthy structured questionnaire that included, among other items, questions about respondents' attitudes toward TLC and its usefulness. Six of the individuals involved in the in-depth interviewing were chosen on the basis of their responses to these attitudinal survey questions. In particular, respondents were selected based on their answers to the three open-ended survey questions inquiring about the benefits gained from using TLC, suggestions they had for improving it, and a request for any additional comments. Their responses were reviewed so as to insure including articulate people who expressed positive attitudes, or negative attitudes, or a mixture of both. The remaining nine interviewees were selected at random in order to make the interview sample more representative. This process of mixed selection and randomized interviewees was intended to insure a broad representation in the interview sample. Because no attempt was made to ensure gender balance in the interview sample, it turned out that all but two of the interviewees were women. The study design allowed for additional interviews if saturation were not reached in the first set of interviews.

\subsection{Interview Data Collection}

Individuals who were recruited for in-depth interviewing were offered a $\$ 5$ phone card as a gift in appreciation of their participation in this phase of the TLC study. Interviews were conducted in person by the first author in peoples' homes, work places, or our offices, depending upon the preference of the interviewee. The second author participated in 12 of the interviews. Interviews lasted between 45 and 60 minutes. All 
interviews were tape recorded, with the interviewees' permission. In addition, both researchers hand-wrote detailed interview notes during the interviews. As explained to interviewees, tapes were intended as back-up to written notes, if needed. Tapes were not transcribed.

Ethnographic interviews were conducted in order to elicit how interviewees conceptualized, reacted to, and attributed meaning to their TLC experience. Consequently, interviews were open-ended so as to probe what interviewees said without constraining them in topic or response. Interviewees were told the purpose of the study, assured of confidentiality, and then asked to describe their use of TLC and what a TLC session was like. If the following topics were not brought up by the interviewee, interviewers asked for interviewees' assessment of benefits they had derived from using TLC, for their reaction to the voice, whether they had received anything in the mail (to explore the usefulness of periodic reports they were mailed), whether they had discussed anything about the study with their doctors, what suggestions they had for TLC per se, what they thought of other possible uses of TLC in health care, what they would tell a family member about TLC, what they thought of the training, and why they called the system as frequently or infrequently as they did. Some participants also were asked whether anyone else in their families had been involved in the TLC conversations. In the course of discussing these topics, interviewees spoke of changes that had occurred in their diets and exercise patterns and of their feelings about using TLC. Most interviewees were very forthcoming and comfortable talking about these topics.

\subsection{Interview Data Analysis}

The authors discussed interview findings during and after the week of interviewing. The first author, who was present at all of the interviews, analyzed her hand-written notes according to four standard methods for analyzing qualitative data: coding, analytic memos, displays, and contextual and narrative analysis (Kaplan and Maxwell 1994). She then compiled a detailed report that provided an analysis and discussion of results. This report was reviewed by the authors and additional members of the TLC project team as a step in insuring validity of results. What follows includes quoted remarks by interviewees and, even when not quoted, an attempt to capture as much of the interviewees' wording as possible (where verbatim quotations were not recorded, much of the wording was), based on the first author's interview notes.

\section{Findings}

Findings are reported for 14 of the 15 individuals who were interviewed. One of the two men who was interviewed was eliminated from interview data analysis because he claimed to have called into the system regularly and explained circumstances of all these calls. It subsequently was found from system logs that, in fact, he had called only once. Because we were concerned that his responses were fabricated, we discarded this interview from analysis.

To aid in interpreting the interviews, we identified several key themes by using a grounded theory approach (Glaser and Strauss,1967; Strauss and Corbin 1990). This paper concentrates on one striking theme from the interviews: how participants related to and formed relationships with TLC. This theme was unanticipated. Interviewees 
were not asked explicitly about relationships they formed with TLC and they had not made comments about it during the survey.

People expressed both positive and negative attitudes toward TLC. Positive reactions included that TLC was "fun," made them more aware of what they ate or how much exercise they did, gave them helpful information, served as a friend or mentor, and helped them change toward a healthier life style. Negative reactions were that TLC talked down to them, treated them like a child, made them feel guilty, had an unpleasant or "disembodied" voice, was inflexible and did not allow them to get or input information they thought important, was boring and repetitive, and did not help them. These responses entailed expression of feelings of guilt, love, and ambiguity or ambivalence, all aspects of forming a personal relationship with the system.

\subsection{Guilt}

The first indication of personal relationship formation emerged during the interviewing when interviewees expressed feelings of guilt evoked by TLC. This finding is related to negative ways in which they described the tone of TLC conversations. Some study participants described the voice they heard on the phone negatively, as a "disembodied" voice from on high or "a man with a tracheotomy." Some thought the voice was synthesized and were surprised to find that a person had made the recordings. As these remarks suggest, they not only thought the voice quality unpleasant, but also felt the tone was problematic. The problematic aspects arose when participants talked about how condescending and condemning TLC was. They felt they were being talked down to, much as their mothers had chided them when they were children. One woman said that she started lying to TLC in order to avoid the lectures she got from it. There was no allowance, they reported, for what they considered reasonable deviations from the behavior TLC was recommending. Nine people wanted to explain to TLC why they could not follow its advice, or they felt that TLC was not flexible enough to take account of their situations. Two individuals wanted to be able to leave messages and three wanted to record comments. People felt constrained by not being able to explain that, for example, they could not walk because there was a blizzard, or could not eat fish because they could not afford it. It seems that these participants felt a need to communicate more than just yes/no or numeric responses to TLC questions. They said they felt guilty about their behavior, or that they were being faulted for something they had reason to have done (or not done).

In addition to the desire to make explanations was the feeling among some interviewees that they were unable to provide information to TLC that would make their inputs more accurate. For example, one woman told of having eaten three donuts over the weekend. Because she called on Monday, and TLC asked only about the previous three days, she could input that she had eaten only three donuts. However, she had really eaten five donuts over the past week, and she wanted to have been able to input that. Mixed in with her apparent concern for accuracy was that she spoke in ways suggesting that she wanted to confess about the additional donuts, raising the idea of her guilt at having eaten them.

These findings of problematic tone and the need to explain and confess go beyond people's sense that the system was rigid and did not allow them to provide explanations or information they wished they could tell it. What is striking is that they felt a need to provide these explanations and information at all, that they cared about what they told 
TLC. This went beyond their sense of responsibility to provide accurate information to what interviewees thought of as a scientific study. The reaction seemed to involve feelings of guilt.

Five people specifically brought up the issue of guilt and said that TLC made them feel guilty. Others said that when they ate the wrong things, they wanted to tell TLC. There was a sense in their comments that they had transgressed and needed to confess, like the woman who had wanted to tell TLC about the extra donuts. As another woman remarked, "I' $m$ Catholic. I know about guilt." Her description of TLC as a "disembodied voice" that came from on high may have added to a sense of sins being known and needing expiation. Others, while not expressing feelings of guilt, brought up issues that may be related: TLC's acting like a conscience, their need to make explanations to TLC, their concerns with accuracy, and their embarrassment at being, as one person described herself, "a loser." All these seem related to some individuals' explicit concern with impression management and ways to look better to TLC. For example, several discussed how they wanted to have their conversations on days when they could report food consumption that would be more in line with TLC recommendations instead of on days (like over the weekend) when they might have eaten too much unhealthy food.

\subsection{Love}

At another end of the reaction spectrum from expressions of guilt were expressions of love. Three women talked in glowing terms about TLC, how it had served as an "unseen friend, a conscience" and a "helper... and mentor." All three said that they continued to call after the end of the study so they could continue the relationship. They spoke of a sense of loss at the abrupt ending of the TLC relationship. One explained it, "I missed that voice, having him say, 'Good morning.' I liked it." Another said she missed him because she got "trained, like Pavlov's dogs." The third felt that the machine replaced her family. It was someone to tell her what to do, like a part of her family.

Two of these people wanted to meet the person whose voice it was. One explained this by saying she wanted to meet the "doctor" on the phone to find out the philosophy of the program and because she "needed human contact." The other spoke in the same way as she might have if she wanted to meet a man who had sounded friendly, attractive, and appealing when he called, for example, by mistake or to conduct a phone survey or had in some other way had made contact without her knowing who he was. She sounded enamored as she said, "Oh, I love the voice. I'd love to meet the man with the voice." These women talked in terms and spoke in tones that gave the sense they had fallen in love with the man whose voice they heard.

\subsection{Ambiguity and Ambivalence}

The forming of personal relationships arose in another way as well. Many participants, regardless of how enthusiastic they were about TLC, referred to the voice as "he" and did not speak of "TLC' or "the system" but, rather, described what "he" said. However, there was ambivalence about whether TLC was a person or a machine. Interviewees differed in their sense of whether they were talking to a machine or to a person when using TLC. There was ambiguity about this, even for the same interviewee, with some calling TLC "him" while also referring to "it" and saying that TLC was a machine. 
Six people talked explicitly of how TLC was a machine and sounded like one. They all seemed negative about the experience and indicated that they would have preferred dealing with a person. Four people made a connection between how people reacted to TLC and how they personally react to machines they consider similar, such as answering machines or automatic teller machines, which they did not like using.

On the other hand, five people explicitly spoke of TLC as though they were speaking of a person. As one put it, "This is my helper. This is my mentor." Four of them described both a personal relationship with TLC and also ways it was like a machine. Two other people compared TLC to a person and, specifically, to family. One person spoke of TLC as a substitute for someone in her family, someone to tell her things. She laughed as she said, "I get attached to a machine. It's like a person." As this remark suggests, there was some ambiguity in whether or not interviewees considered "him" a person or a machine. Interviewees indicated that there were advantages in having it both ways.

One advantage of this ambivalence arose when two women discussed such personal issues as loneliness, self-esteem, and depression. They related these issues to their interaction with TLC in ways that sounded as though TLC could function as a psychiatrist or psychological counselor for them. The anonymity of interacting with a machine apparently helped them do this. One of these women was very positive about her experience with TLC. She was the woman who thought of TLC as a family member. The other, who was negative toward TLC, spoke of how it could provide an outlet for something akin to counseling or friendship. "A lot of people don't have anyone to talk to. A computer is anonymous," she said, and much later in the interview, she remarked, "It shouldn't be a psychic hot-line."

\section{Discussion: Personal Relationship}

Despite the ambiguity and ambivalence described above, on the whole, people spoke of their interaction with TLC in the same kind of terms as they would have used if they were describing interaction with a person. Many indicated that they would have preferred human contact to that of a machine. Even so, even those who felt TLC was "disembodied," even those who said they wished they had been able to talk to a person instead of to the recorded voice, referred to "him." It seems as though participants were forming personal relationships with TLC, or, at least, with the person whose voice they heard.

This interpretation provides a connection between those who felt guilt and those who felt love. Although at different ends of the reaction spectrum, guilt and love both involve personal relationships. In both cases, as well as in expressions of ambiguity and ambivalence, these feelings were evoked by the relationship people formed with TLC. As with the women who thought of using TLC as a possible psychological encounter, interviewees who expressed guilt or love seemed to identify with TLC, and to project onto it human emotion and a personal relationship.

\section{Conclusions}

That people formed personal relationships with a system such as TLC raises important issues. Profoundly felt ethical concerns accompanied development of computer systems 
(e.g. Weiner 1964). When using this technology for artificial intelligence, issues can become so threatening as to be actively suppressed (see, e.g., Dreyfus and Dreyfus 1986). Weizenbaum (1976) was profoundly disturbed that people felt so personally involved in his ELIZA program, which simulated a Rogerian therapist, that they requested privacy while using the computer. An incident of this kind with his secretary provoked him to consider the ethical implications of computer use and resulted in his powerful crie de coeur that we, as information systems developers, implementers, users, and advocates, should consider the morality of what we do.

Turkle (1984) described numerous ways in which people project personalities and values onto computers and how people develop personal relationships with computer systems. As computer systems became more fluid, she presented new studies of how people take on different identities through computer use (Turkle 1995). Her work illustrates powerful ways in which information technology raises issues of identity and psychological projection.

The TLC study suggests that people had reactions to a computer-based simulated telephone conversation that are similar to those Turkle described. Individuals appeared to form personal relationships and identify with TLC, and to describe TLC in human-like terms, where their interface with this computer system was through a pre-recorded telephone voice and telephone key-pad. These findings raise both research and ethical issues. Among questions to be considered for future study are:

(1) What accounts for the kind of relationship individuals formed with TLC?

(2) How was this relationship affected by the nature of the interface, e.g., a computer-mediated conversation vs. direct use of a computer keyboard and display terminal?

(3) What ethical considerations are involved in creating or promoting systems with which people form deep personal ties?

(4) What implications does this personal relationship formation have for systems design implementation, and research?

\section{References}

Adams H. The Education of Henry Adams. Boston: Houghton Mifflin Co., 1918, 1961.

Balas, E. A.; Boren, S. A., and Griffing, G. "Computerized Management of Diabetes: A Synthesis of Controlled Trials," in Proceedings of the AMIA Fall Symposium, C. G. Chute (ed.). Philadelphia: Hanley \& Belfus, Inc., 1998, pp. 295-299.

Dreyfus, H. L., and Dreyfus, S. E. Mind Over Machine: The Power of Human Intuition and Expertise in the Era of the Computer. New York: The Free Press, 1986.

Forsythe, D. "New Bottles, Old Wine: Hidden Cultural Assumptions in a Computerized Explanation System for Migraine Sufferers," Medical Anthropology Quarterly (10), 1996, pp. 551-574.

Friedman, R. H. "Automated Telephone Conversations to Assess Health Behavior and Deliver Behavioral Interventions," Journal of Medical Systems (22), 1998, pp. 95-101.

Friedman, R. H.; Stollerman, J. E.; Mahoney, D. M.; and Rozenblyum, L. "The Virtual Visit: Using Telecommunications Technology to Take Care of Patients," Journal of the American Medical Informatics Association (4), 1997, pp. 413-425.

Friedman, R. H.; Stollerman, J.; Rozenblyum, L.; Belfer, D.; Selim, A.; Mahoney, D.; and Steinbach, S. "A Telecommunications System to Manage Patients with Chronic Disease," in MedInfo '98: Proceedings of the Ninth World Congress on Medical Informatics, B. Cesnik, A. T. McCray, and J-R. Scherrer (eds.), IOS Press, 1998, pp. 1330-1334. 
Glaser, B. G., and Strauss, A. L. The Discovery of Grounded Theory: Strategies for Qualitative Research. New York: Aldine, 1967.

Hunt, D. L.; Haynes, B.; Hayward, R. S. A.; Pim, A. M; and Horsman, J. "Automated Directfrom-patient Information Collection for Evidence-based Diabetes Care," in Proceedings of the AMIA Fall Symposium, D. R. Massys (ed.). Philadelphia: Hanley \& Belfus, Inc., 1997, pp. 81-85.

Kaplan, B. “Addressing Organizational Issues into the Evaluation of Medical Systems," Journal of the American Medical Informatics Association (4), 1997, pp. 94-101.

Kaplan, B. and Duchon, D. "Combining Qualitative and Quantitative Methods in Information Systems Research: A Case Study,” MIS Quarterly (12), 1988, pp. 571-586.

Kaplan, B., and Maxwell, J. "Qualitative Methods for Evaluating Computer Information Systems," in Evaluating Health Care Information Systems: Methods and Applications, J. G. Anderson, C. E. Aydin, and S. J. Jay (eds.). Thousand Oaks, CA: Sage Publications, 1994, pp. 45-68.

Kim, J.; Trace, D.; Meyers, K.; and Evens, M. "An Empirical Study of the Health Status Questionnaire System for Use in Patient-computer Interaction," in Proceedings of the AMIA Fall Symposium, D. R. Massys (ed.). Philadelphia: Hanley \& Belfus, Inc., 1997, pp. 86-90.

Nelson, T. Computer Lib/Dream Machines, $1^{\text {st }}$ ed. [n.p.], 1974.

Rae, J. B. The American Automobile: A Brief History. Chicago: The University of Chicago Press, 1965.

Shortliffe, E. H. "Dehumanization of Patient Care: Are Computers the Problem or the Solution?" Journal of the American Medical Informatics Association (1), 1994, pp. 76-78.

Strauss, A., and Corbin, J. Basics of Qualitative Research: Grounded Theory Procedures and Techniques. Newbury Park, CA: Sage Publications, 1990.

Turing, A. M. "Computing Machinery and Intelligence," Mind (59:236), 1950.

Turkle, S. "Computer as Rorschach," Society (17:2), 1980, pp. 15-24. Reprinted in Managing Computers in Health Care: A Guide for Professionals, J. A. Worthley (ed.). Ann Arbor, MI: AUPHA Press, 1982, pp. 223-243.

Turkle, S. The Second Self: Computers and the Human Spirit. New York: Simon and Schuster, 1984.

Turkle, S. Life on the Screen: Identity in the Age of the Internet. New York: Simon and Schuster, 1995.

Weiner, N. God and Golem, Inc.: A Comment on Certain Points where Cybernetics Impinges on Religion. Cambridge, MA: The MIT Press, 1964.

Weinzenbaum, J. Computer Power and Human Reason: From Judgment to Calculation. San Francisco: W. H. Freeman and Company, 1976.

Zuboff, S. In the Age of the Smart Machine: The Future of Work and Power. New York: Basic Books, 1988.

\section{About the Authors}

Bonnie Kaplan, Ph.D., is a Lecturer at the Yale School of Medicine's Center for Medical Informatics, a Senior Scientist at Boston University's Medical Information Systems Unit, and President of Kaplan Associates. A recognized expert in evaluating clinical applications of computer information systems, she is the author of over 30 refereed papers as well as numerous other articles and publications. She has worked with the U.S. Department of Veterans Affairs (VA) and the U.S. National Institute of Standards and Technology (NIST); the Universities of Pittsburgh, Cincinnati, and Chicago; and Yale, Boston, Harvard, and Johns Hopkins Universities. She is on the Informatics Advisory Board of the Pharmaceutical Research Institute of Bristol-Myers 
Squibb, serves as Chair of the American Medical Informatics Association People and Organizational Issues Working Group, and as editor of the International Medical Informatics Association Working Group-13 (Organizational Impacts) newsletter. She has taught a variety of information systems courses in business administration and hospital administration programs at several universities. She holds a Ph.D. from the University of Chicago. E-mail: Bonnie.Kaplan@ yale.edu.

Ramesh Farzanfar received her Ph.D. in political science from Massachusetts Institute of Technology with a concentration in political communications and behavior and developmental politics. She has used ethnographic research methods in both her Master's thesis and her Ph.D. dissertation for which she interviewed 10 groups and 25 individuals respectively. She has taught at Mount Holyoke College and currently is a Research Associate/Systems Analyst at the Medical Information Systems Unit, Boston University Medical Center.

Robert H. Friedman, M.D., is an Associate Professor of Medicine (General Internal Medicine) and Public Health and Director of the Medical Information Systems Unit (MISU) at Boston University Medical Center. The MISU is a research and development units with a staff of eight clinicians, programmers and analysts and a number of trainees, working to create and evaluate computer systems that help physicians take care of patients. Dr. Friedman is also the director of the General Internal Medicine Fellowship Program at the Medical Center, a program that trains future general internal medicine faculty in research and teaching methods. Dr. Friedman is currently or has been the principal investigator on 22 externally funded research grants including $13 \mathrm{NIH}$ grants. The research areas have included computer-based decision support, telecommunications, and medical education, with an emphasis on primary care, geriatrics, and cardiovascular disease and health behavior. 